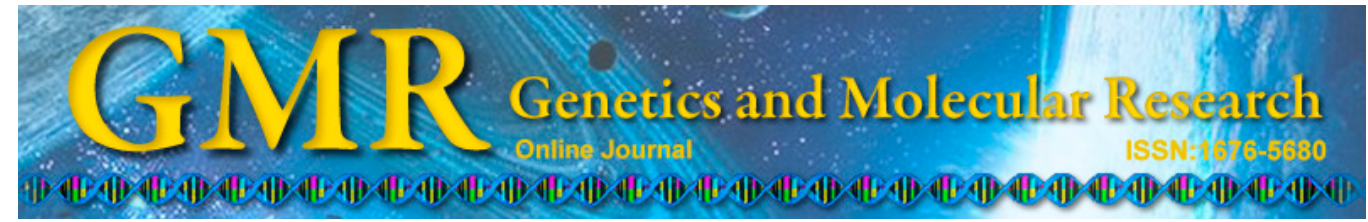

\title{
Association of the $A p o E$ gene polymorphism and dietary factors with cerebral infarction and circulating lipid concentrations
}

\author{
H.-Q. Yan, Y. Yuan, P. Zhang, Z. Huang, L. Chang and Y.-K. Gui \\ Department of Neurology, First Affiliated Hospital of Xinxiang Medical College, \\ Xinxiang, China \\ Corresponding author: H.-Q. Yan \\ E-mail: yanhai_qing@yeah.net \\ Genet. Mol. Res. 14 (1): 665-670 (2015) \\ Received June 14, 2014 \\ Accepted November 18, 2014 \\ Published January 30, 2015 \\ DOI http://dx.doi.org/10.4238/2015.January.30.9
}

\begin{abstract}
The aim of this study was to explore the relationship between the ApoE gene polymorphism and dietary factors with stroke and circulating lipid levels in the Chinese population. We selected 580 patients with stroke and 580 age- and gender-matched healthy controls, and examined their $A p o E$ polymorphism genotype using the polymerase chain reaction-restriction fragment length polymorphism (PCR-RFLP) method. We also analyzed the relationship between the $A p o E$ gene polymorphism and dietary factors as well as plasma lipid concentrations in this cohort. We detected six $A p o E$ genotypes in the study populations, and determined that the E4 allele was positively associated with cerebral infarction (CI), whereas allele E2 was negatively associated with total cholesterol (TC) and low-density lipoprotein-cholesterol levels. The dietary habits of the subjects with descending order of average total TC and triglyceride levels were: subjects addicted to oily food $>$ subjects addicted to sweets $>$ subjects addicted to smoking $>$ subjects addicted to alcohol $>$ subjects following a vegetarian diet $(\mathrm{P}<0.05)$. Our results demonstrated that the ApoE gene polymorphism was associated with a risk for $\mathrm{CI}$ in a Chinese population.
\end{abstract}

Key words: Cerebral infarction; Lipids; Dietary factors; ApoE gene polymorphism 


\section{INTRODUCTION}

Apolipoprotein E (ApoE) is one of the main apolipoproteins comprising human plasma lipoproteins. ApoE can transport cholesterol and regulate lipid metabolism, and has become the focal point of recent studies (Al Harthi et al., 2014; Berkinbayev et al., 2014; Zurnić et al., 2014). In recent years, as the development of molecular biology and genetic engineering technologies has progressed, studies have demonstrated a close association between the ApoE gene polymorphism and serum lipid levels (Shin et al., 2014; Yin et al., 2014; Zhu et al., 2014). It has also been found that dietary factors had some impact on blood lipids, and that this effect could be modified by receptor lipoprotein metabolism (Petkeviciene et al., 2012; Rudkowska et al., 2013). Research data showed that the $A p o E$ polymorphism had a highly significant impact on lipid concentrations (Petkeviciene et al., 2012; Rudkowska et al., 2013). However, environmental factors, including living conditions, diet, and living habits, were also shown to affect blood lipid levels and cerebral infarction (CI) (Egert et al., 2012; Petkeviciene et al., 2012; Rudkowska et al., 2013). Therefore, this study focused on the relationship between the ApoE gene polymorphism and dietary factors in the association with plasma lipid concentrations.

\section{MATERIAL AND METHODS}

\section{Subjects}

All participants were enrolled from January 2009 to March 2013 in the Department of Neurology, First Affiliated Hospital of Xinxiang Medical College. This study was approved by the ethics committee of the First Affiliated Hospital of Xinxiang Medical College. All subjects were informed of the purpose and significance of this study and signed the consent forms. The fasting total cholesterol (TC), triglycerides (TG), and high- and low-density lipoproteincholesterol (HDL-C and LDL-C, respectively) levels were examined according to Xie et al. (2013). In total, 580 patients with CI and 580 normal control subjects were enrolled in the study. These two groups were age- and gender-matched. Dietary and lifestyle habits were surveyed in these subjects according to methods described in our previous study (Xie et al., 2012). Diagnostic criteria of CI were as referred to in the 4th Amendment of the National Stroke Conference ( $\mathrm{Li}$ et al., 2007), and the diagnosis was confirmed by brain computerized tomography/magnetic resonance imaging (CT/MRI). Patients with the following conditions were excluded from the study: peripheral vascular disease or peripheral vascular occlusive disease, arteritis, blood diseases, tuberculosis, cancer, severe liver or kidney dysfunction, or use of lipid-lowering drugs within one week prior to admission.

\section{Methods}

All subjects who had lipid testing fasted for more than $12 \mathrm{~h}$ before blood extraction, and were forbidden alcohol and a high-fat diet; the venous blood was drawn in the morning, and an aliquot of the blood sample was utilized for lipid determination [TC (mM), TG (mM), HDL-C (mM), and LDL-C (mM)] using an automatic biochemical analyzer (Shanghai Glorious Medical Devices Co., Ltd., Shanghai, China). The remaining blood samples were 
collected into an ethylenediaminetetraacetic acid (EDTA) anticoagulant vial, mixed quickly, and stored at $-20^{\circ} \mathrm{C}$ for subsequent processing.

\section{DNA extraction}

A sample of $2 \mathrm{~mL}$ fasting venous blood was taken from the antecubital vein and placed into EDTA-containing vials. The genomic DNA extraction kit (Promega Corporation; Madison, WI, USA) was used for genomic DNA extraction from blood samples of the subjects according to the manufacturer protocol.

\section{Polymerase chain reaction (PCR) amplification of the $A p o E$ gene}

Primers were designed according to basic principles and the known ApoE gene sequence (NC_000019.10). Primers were designed by Shanghai Sangon Biotech (Shanghai, China). P1: 5'-ACA GAA CGC CCC GGC CTG GTA CAC-3'; P2: 5'-TAA GCT YGG CAC GGC TGT CCA AGG A-3'. The PCR amplification reaction mix $(30 \mu \mathrm{L})$ comprised $2 \mu \mathrm{L}$ genomic DNA, $3 \mu \mathrm{L}$ 10X Buffer (with magnesium), $2 \mu \mathrm{L} 4 \mathrm{X}$ dNTPs, $1 \mu \mathrm{L}$ of each upstream and downstream primer, $0.2 \mu \mathrm{L}$ TaqDNA polymerase, and $21 \mu \mathrm{L}$ sterile double-distilled water. PCR conditions were as follows: $94^{\circ} \mathrm{C}$ predenaturation for $5 \mathrm{~min}$, followed by $94^{\circ} \mathrm{C}$ denaturation for $50 \mathrm{~s}, 67^{\circ} \mathrm{C}$ annealing for $50 \mathrm{~s}$, and $72^{\circ} \mathrm{C}$ extension for $50 \mathrm{~s}$ over 30 cycles, with a final extension at $72^{\circ} \mathrm{C}$ for $7 \mathrm{~min}$, holding at $4{ }^{\circ} \mathrm{C}$ for preservation. The resulting products were used for $2 \%$ agarose gel electrophoresis; the specific 265 -bp amplified fragments were visualized under ultraviolet light.

\section{ApoE genotyping}

Restriction digestion conditions were as follows: $0.5 \mu \mathrm{L} H \mathrm{HaI}$ restriction enzyme (Takara Bio; Otsu, Shiga, Japan), $1 \mu \mathrm{L}$ 10X Buffer, and $0.5 \mu \mathrm{L}$ sterile double-distilled water were added to $8 \mu \mathrm{L} 50 \mathrm{ng} / \mu \mathrm{L}$ PCR amplification products and incubated for $6 \mathrm{~h}$ at $37^{\circ} \mathrm{C}$. Digestion products were added to $8 \%$ polyacrylamide gel wells in sample plates, subjected to $8 \mathrm{~V} / \mathrm{cm}$ vertical electrophoresis for $1.5 \mathrm{~h}$, and the gel was stained for $30 \mathrm{~min}$ with ethidium bromide before washing. Under ultraviolet light photography, they were compared with the molecular weight DNA MarkeDigestion, products were analyzed by vertical polyacrylamide gel electrophoresis $(8 \% ; 8 \mathrm{~V} / \mathrm{cm}$ for $8 \mathrm{~h})$, stained for $30 \mathrm{~min}$ with ethidium bromide, washed, and visualized under ultraviolet light photography against the molecular weight Marker-B band (Bioteck, Beijing, China). Expected digestion products for each genotype were: E2/2: 91, 83, and $61 \mathrm{bp}$; E3/3: 91, 61, 48, and $35 \mathrm{bp}$; E4/4: 72, 61, 48, and $35 \mathrm{bp}$; E2/3: 91, 83, 61, 48, and $35 \mathrm{bp}$; E2/4: 91, 83, 72, 61, 48, and $35 \mathrm{bp}$; and E3/4: 91, 72, 61, 48, and $35 \mathrm{bp}$.

\section{Statistical analysis}

Lipid levels are reported as means \pm standard deviation (SD), allele frequencies were calculated using the allele counting method, and the SPSS 10.0 software package (SPSS; Chicago, IL, USA) was used for statistical analysis. Continuous data were compared using the Student $t$-test, and categorical data between groups were compared using the chi-square test. Two-sided $\mathrm{P}<0.05$ was considered to be statistically significant. 


\section{RESULTS}

\section{Two-group comparisons of gender, age, and blood lipid concentrations}

Gender and age were compared between the CI and normal control groups and showed no significant difference $(\mathrm{P}>0.05)$, suggesting that gender and age were matched in the two groups. TC, TG, HDL-C, and LDL-C levels in the two groups were compared between the groups, and the results are shown in Table 1.

Table 1. Characteristics of the participant population.
\begin{tabular}{lccccccc}
\hline Groups & $\mathrm{N}$ & Male [N (\%)] & Age (years) & TG $(\mathrm{mM})$ & TC $(\mathrm{mM})$ & HDL-C $(\mathrm{mM})$ & LDL-C $(\mathrm{mM})$ \\
\hline CI group & 580 & $387(66.7)$ & $59.8 \pm 13.7$ & $3.0 \pm 1.8$ & $5.5 \pm 2.6$ & $1.0 \pm 0.6$ & $2.9 \pm 1.6$ \\
Control group & 580 & $379(65.3)$ & $59.4 \pm 13.1$ & $1.7 \pm 1.0$ & $4.4 \pm 2.1$ & $1.6 \pm 0.8$ & $2.2 \pm 1.0$ \\
P & & & 0.878 & $<0.001$ & $<0.001$ & 0.065 & 0.087 \\
\hline
\end{tabular}

$\mathrm{CI}=$ cerebral infarction; $\mathrm{TG}=$ triglycerides; $\mathrm{TC}=$ total cholesterol; HDL-C $=$ high-density lipoprotein cholesterol; LDL-C $=$ low-density lipoprotein cholesterol.

\section{Relationship between CI, diet, and blood lipid levels}

In 378 cases of patients with CI, the dietary habits were associated with descending order of average TC and TG levels as follows: subjects addicted to oily food > subjects addicted to sweets $>$ subjects addicted to smoking $>$ subjects addicted to alcohol $>$ subjects following a vegetarian diet. Average TC and TG levels were significantly higher in subjects addicted to oily food, sweets, smoking, or drinking than those in subjects following a vegetarian diet $(\mathrm{P}<0.01)$ (Table 2).

Table 2. Diet and lipids in CI patients.
\begin{tabular}{lccc}
\hline Diet & N & TC (mM) & TG (mM) \\
\hline Oily food & 121 & $6.1 \pm 1.0^{*}$ & $3.9 \pm 1.5^{*}$ \\
Sweets & 109 & $5.7 \pm 2.0^{*}$ & $3.8 \pm 1.6^{*}$ \\
Smoking & 165 & $5.5 \pm 1.7^{*}$ & $2.7 \pm 1.4^{*}$ \\
Alcohol drinking & 116 & $5.3 \pm 1.98$ & $2.5 \pm 1.6^{*}$ \\
Vegetarian & 69 & $4.9 \pm 1.7$ & $2.2 \pm 1.4$ \\
\hline
\end{tabular}

$* \mathrm{P}<0.05$, compared with vegetarian. $\mathrm{CI}=$ cerebral infarction; $\mathrm{TC}=$ total cholesterol; $\mathrm{TG}=$ triglycerides.

\section{Two-group comparison of $A p o E$ genotype and allele frequency distributions}

As shown in Table 3, there were no significant differences in the distribution of E2/3, $\mathrm{E} 2 / 4$, and $\mathrm{E} 3 / 3$ genotypes between the two groups $(\mathrm{P}>0.05)$. E3/4 and E4/4 genotype frequencies in the CI group were significantly higher than those in the normal control group (both $\mathrm{P}<0.05$ ). The frequency of the E2/2 genotype was lower in the CI group than that in the control group $(\mathrm{P}<0.05)$, and the $\mathrm{E} 2$ allele frequency was also lower in the CI group than that in the control group $(\mathrm{P}<0.05)$. The E4 allele frequency, however, was higher in the CI group than that in the control group $(\mathrm{P}<0.01)$. E3 allele frequencies showed no significant difference between the two groups $(\mathrm{P}>0.05)$. 
Table 3. Distribution of genotypes and alleles.

\begin{tabular}{|c|c|c|c|c|c|c|c|c|c|c|}
\hline \multirow[t]{2}{*}{ Groups } & \multirow[t]{2}{*}{$\mathrm{N}$} & \multicolumn{6}{|c|}{ Genotypes [N (\%)] } & \multicolumn{3}{|c|}{ Alleles } \\
\hline & & $\mathrm{E} 2 / 2$ & $\mathrm{E} 2 / 3$ & $\mathrm{E} 2 / 4$ & $\mathrm{E} 3 / 3$ & E3/4 & $\mathrm{E} 4 / 4$ & E2 & E3 & E4 \\
\hline CI & 580 & $11(1.9)^{*}$ & $41(7.1)$ & $33(5.7)$ & $351(60.5)$ & $82(1.4)^{*}$ & $62(10.7)^{*}$ & $96(8.3)^{*}$ & $825(71.1)$ & $239(20.6)^{*}$ \\
\hline Control & 580 & $61(10.5)$ & $54(9.3)$ & $49(8.4)$ & $354(61.0)$ & $33(0.6)$ & $29(2.5)$ & $225(19.4)$ & $795(68.5)$ & $140(12.1)$ \\
\hline
\end{tabular}

$* \mathrm{P}<0.05$, compared to control group. $\mathrm{CI}=$ cerebral infarction.

\section{DISCUSSION}

Many factors can affect blood lipid levels, such as age, gender, weight, diet, and lifestyle. Studies have shown that lipid levels between the genders were not significantly different. With the increase of age and weight, lipid levels tend to increase. Although age and gender represent immutable factors, weight, diet, and lifestyle can be modified. Therefore, more attention should be paid to the influence of dietary factors on plasma lipid levels for inclusion in future studies. Our research showed that different dietary patterns had differing impacts on blood lipid levels: subjects addicted to fat, sweets, tobacco, and alcohol-containing diets had significantly elevated blood lipid levels as compared with subjects following a vegetarian diet. The impact of smoking on human health has been recognized by researchers as well as the public, with the hazards proportional to the duration of the smoking habit and the number of daily cigarettes smoked (Simino et al., 2014). This study demonstrated that smokers had elevated serum cholesterol and TG levels. This might be due to a variety of compounds in tobacco, including the primary compounds nicotine and carbon monoxide, as animal experimentation has proven that nicotine and carbon monoxide in tobacco may elevate TG levels. Thus, the hazards of smoking can be partly attributed to its effects on lipoprotein levels (Jung et al., 2014). Smoking was not shown to be associated with gender, age, body mass index, or blood pressure levels; rather, it was associated with the independent factor of lipid metabolism (Jung et al., 2014). In addition, this study also showed that alcohol drinking significantly increased lipid levels. Long-term intake of high concentrations of alcohol has recently been shown to induce weakened ApoE expression in the mouse liver (Jung et al., 2014). It also had an impact on lipid levels. In this study, we found that the ApoE allele frequency distribution in both the CI and control groups had the same trend, and that the allele frequencies of the highest frequency allele, E3, did not differ significantly between groups. Alleles E2 and E4 were relatively low in frequency, but allele E2 was significantly more frequent in the control than that in the CI group, whereas allele E4 showed the opposite pattern, which was significant as well. The $A p o E$ E4 allele might therefore be a susceptibility gene and risk factor for $\mathrm{CI}$, and the $\mathrm{E} 2$ allele might serve as a protective factor.

In summary, the results of our study demonstrated that the $A p o E$ gene polymorphism significantly affected the risk for CI, and showed interaction with dietary factors.

\section{REFERENCES}

Al Harthi F, Huraib GB, Zouman A, Arfin M, et al. (2014). Apolipoprotein e gene polymorphism and serum lipid profile in Saudi patients with psoriasis. Dis. Markers 2014: 239645.

Berkinbayev S, Rysuly M, Mussayev A, Blum K, et al. (2014). Apolipoprotein gene polymorphisms (APOB, APOC111, APOE) in the development of coronary heart disease in ethnic groups of Kazakhstan. J. Genet. Syndr. Gene Ther. 5: 216. 
Egert S, Rimbach G and Huebbe P (2012). ApoE genotype: from geographic distribution to function and responsiveness to dietary factors. Proc. Nutr. Soc. 71: 410-424.

Li D, Zhao WQ and Tian YQ (2007) Clinical studies of insulin and magnesium sulfate George acute cerebral infarction. Zhong Feng Yu Shen Jing Xi Tong Ji Bing 56: 216-218.

Jung C, Kaul MG, Bruns OT, Dučić T, et al. (2014). Intraperitoneal injection improves the uptake of nanoparticle-labeled high-density lipoprotein to atherosclerotic plaques compared with intravenous injection: A multimodal imaging study in ApoE knockout mice. Circ. Cardiovasc. Imaging 7: 303-11.

Petkeviciene J, Smalinskiene A, Luksiene DI, Jureniene K, et al. (2012). Associations between apolipoprotein E genotype, diet, body mass index, and serum lipids in Lithuanian adult population. PLoS One 7: e41525.

Rudkowska I, Dewailly E, Hegele RA, Boiteau V, et al. (2013). Gene-diet interactions on plasma lipid levels in the Inuit population. Br. J. Nutr. 109: 953-961.

Shin MH, Choi JS, Rhee JA, Lee YH, et al. (2014). APOE polymorphism and carotid atherosclerosis in Korean population: the Dong-gu Study and the Namwon Study. Atherosclerosis 232: 180-185.

Simino J, Kume R, Kraja AT, Turner ST, et al. (2014). Linkage analysis incorporating gene-age interactions identifies seven novel lipid loci: The Family Blood Pressure Program. Atherosclerosis 235: 84-93.

Xie X, Ma YT, Yang YN, Li XM, et al. (2012). Serum uric acid levels are associated with polymorphism in the SAA1 gene in Chinese subjects. PLoS One 7: e40263.

Xie X, Ma YT, Yang YN, Li XM, et al. (2013). SAA1 genetic polymorphisms are associated with plasma glucose concentration in non-diabetic subjects. Clin. Chem. Lab. Med. 51: 2331-2334.

Yin YW, Qiao L, Sun QQ, Hu AM, et al. (2014). Influence of apolipoprotein E gene polymorphism on development of type 2 diabetes mellitus in Chinese Han population: a meta-analysis of 29 studies. Metabolism 63: 532-541.

Zhu S, Wang Z, Wu X, Shu Y, et al. (2014). Apolipoprotein E polymorphism is associated with lower extremity deep venous thrombosis: color-flow Doppler ultrasound evaluation. Lipids Health Dis. 13: 21.

Zurnić I, Djurić T, Koncar I, Stanković A, et al. (2014). Apolipoprotein E gene polymorphisms as risk factors for carotid atherosclerosis. Vojnosanit. Pregl. 71: 362-367. 